\title{
CONSERVADORISMO CONDICIONAL EM FUNÇÃO DE DEMANDA E SINALIZAÇÃO INFORMACIONAL NO MERCADO BRASILEIRO
}

\section{CONDITIONAL CONSERVATISM AS FUNCTION OF INFORMATIONAL DEMAND AND SIGNALING IN BRAZILIAN MARKET}

\section{CONSERVADURISMO CONDICIONAL EN FUNCIÓN DE DEMANDA Y SEÑALIZACIÓN INFORMACIONAL EN EL MERCADO BRASILEÑO}

Recebido em: 14/12/2018

Avaliado em: 23/05/2019

Reformulado em:05/06/2019

Aceito para publicação em: 18/07/2019

Publicado em: 22/07/2019

Editor Responsável: Tarcísio Pedro da Silva
Lineker Costa Passos ${ }^{1}$

Antonio Carlos Coelho ${ }^{2}$

\section{RESUMO}

Investigaram-se interações entre demanda por categoria de investidores institucionais e sinalização de gestores em torno de qualidade informacional eficiente; esta foi mensurada pelo conservadorismo condicional (CC) resultante do reconhecimento tempestivo assimétrico de perdas (ALRT); 361 firmas listadas na B3 (4.408 observações-ano) foram a amostra da pesquisa, com dados do período 19982015. Conservadorismo condicional foi estimado segundo Ball e Shivakumar (2005) e participação relevante de investidores institucionais na base acionária e em órgãos diretivos das firmas foi a proxy para demanda informacional. MQO múltiplo com estimação por GMM - System balizaram os testes processados. Constatou-se que a demanda informacional de investidores sofisticados incrementa com significância o nível de ALRT para todas as categorias amostradas (Fundo de Pensão e de Investimentos, Instituição Financeira, Seguradoras e Administradores de Carteiras); já o CC apenas não se manifesta para esta última categoria. Sob a hipótese de ALRT e CC, inferiu-se que a demanda dessas categorias influenciou a sinalização da informação contábil eficiente por gestores, o que implica que informações sobre a situação econômica das firmas importam para investidores sofisticados. O estudo fornece evidências de que, mesmo em países com ambiente institucional com escasso incentivo econômico, o reporte de informações contábeis eficientes atende à demanda informacional de classes de investidores sofisticados; assim, se contribui para futuras agendas de pesquisa que se dediquem a maior aprofundamento de tal questão em outros mercados de capital similares ao do Brasil.

Palavras-Chave: Demanda Informacional, Sinalização Eficiente, Investidores Sofisticados, Categorias de Investidores Institucionais, Conservadorismo Condicional.

\footnotetext{
${ }^{1}$ Mestre em Administração e Controladoria pela Universidade Federal do Ceará; Professor do EBTT - Contabilidade Instituto Federal do Piauí; E-mail: linekerpassos@gmail.com

${ }^{2}$ Doutor em Contabilidade pela Universidade de São Paulo; Professor Visitante no PPAC Universidade Federal do Ceará; E-mail: accoelho47@gmail.com
} 


\section{ABSTRACT}

We investigate interactions between demand of institutional investor categories and managers' signaling concerning efficient information quality, which was measured by conditional conservatism (CC) resultant of asymmetric loss recognition timeliness (ALRT); 361 B3 listed firms (4,408 observations-year) composed the study sample, with data covering 1998-2015 period. We estimate conditional conservatism according to Ball and Shivakumar (2005) and institutional investors' relevant participation as shareholder and firm's board member was the proxy for informational demand. Multiple OLS with GMM - System estimation were the basis of the processed tests. We found that sophisticated investors informational demand significantly contributes to increase ALRT level for all sampled categories (Pension and Investment Fund, Financial Institution, Insurance Companies and Portfolio Managers); CC was not significant to the latter category. Under the hypothesis of ALRT and CC, it was inferred that the demand of these categories influenced the signaling of efficient accounting information by managers, which implies that information about firms' economic situation matters for sophisticated investors. The study provides evidence that even in countries with an institutional environment with low economic incentive, the reporting of efficient accounting information responds to sophisticated investors informational demand; thus, we contributes to future research agendas dedicated to furthering this issue in other capital markets similar to Brazil.

Keywords: Informational Demand; Efficient Signaling; Sophisticated Investors; Categories of Institutional Investors; Conditional Conservatism.

\section{RESUMEN}

Investigamos las interacciones entre la demanda por categoría de inversionistas institucionales y la señalización de los gerentes sobre la calidad de la información eficiente; esto se midió por el conservadurismo condicional (CC) resultante de lo reconocimiento anticipado asimétrico de pérdidas (ALRT); 361 firmas listadas en B3 (4.408 observaciones-año) fueron la muestra del estudio, con datos del período 1998-2015. El conservadurismo condicional se estimó de acuerdo con Ball y Shivakumar (2005) y la participación relevante de los inversionistas institucionales en la base de accionistas y en órganos directivos de las firmas representó la demanda informativa. Múltiples MCO con estimación por GMM - System fueron la base de las pruebas procesadas. Descubrimos que la demanda informativa de los inversionistas sofisticados aumenta significativamente el nivel de ALRT para todas las categorías muestreadas (Fondo de Pensiones e Inversiones, Instituciones Financieras, Compañías de Seguros y Administradores de Cartera); CC sólo no se manifiesta a la última categoría. Bajo la hipótesis de ALRT y CC, se infirió que la demanda de estas categorías influyó en la señalización de información contable eficiente por parte de los gerentes, lo que implica que la información sobre la situación económica de las empresas es importante para los inversionistas sofisticados. El estudio proporciona evidencia de que incluso en países con un entorno económico con un incentivo económico bajo, la notificación de información contable eficiente responde a la existencia de una demanda informativa de los inversionistas, lo que contribuye a futuras agendas de investigación que se dedican a investigar este problema en otros mercados de capital similares a Brasil.

Palabras-clave: Demanda Informacional; Señalización Eficiente; Inversores Sofisticados; Categorías de Inversores Institucionales Conservadurismo Condicional.

\section{INTRODUÇÃO}

Sob a égide da teoria contratual da firma, gestores são os agentes detentores de maior nível de informações sobre a firma em face dos demais agentes contratantes; essa assimetria informacional 
pode os levar, mantidas as demais condições constantes, a avaliações diferenciadas da firma, o que requer dos gestores mecanismos de sinalização em busca de maior homogeneidade (menor dispersão de interesses) para investidores e stakeholders (Akerlof, 1970; Connelly et al., 2011; Spence, 1973).

Dentre os atributos que contribuíram para sinalização, destaca-se a prática do conservadorismo condicional na divulgação de informações contábeis; a presença de tal atributo na informação contábil sinaliza a decisão de gestores em informar perdas econômicas prováveis (Coelho, 2007), reduzindo assimetria informacional entre gestores e investidores acerca do nível de proteção aos fluxos futuros de caixa.

Watts (2003) argumenta que tal atributo representa meio de mitigar efeitos de risco moral associado aos gestores e em detrimento das partes contratantes da firma, em virtude de informações imperfeitas, payoffs assimétricos e horizontes amplos de decisão de gestores em confronto com sua responsabilidade limitada.

Basu (1997), ao definir o conservadorismo condicional como a tendência de contadores de requerer maior grau de verificação para reconhecer good news em comparação ao reconhecimento de bad news ressalta que é esperado que lucros divulgados reflitam perdas econômicas de forma mais tempestiva que ganhos econômicos, em decorrência do registro antecipado assimétrico de perdas econômicas (Coelho, 2007).

A presença desse atributo no lucro contábil reportado por gestores, se dará, segundo Watts (2003), na medida da demanda dos usuários da informação contábil; esta demanda funcionaria, então, como incentivo econômico à sinalização de gestores e contadores sobre os fluxos futuros (Coelho, Cia \& Lima, 2010). Nesse contexto, Ball (2001) e Watts (2003) propõem que investidores não ingênuos seriam relevante fonte de demanda informacional como mecanismo de proteção de seus recursos aportados, incentivando a decisão de preparar demonstrações contábeis com sinais de conservadorismo condicional na informação sobre a situação econômica da empresa, registro que depende da discricionariedade da gestão.

Ramalingegowda e Yu (2012) classificam tais investidores como sofisticados, ou seja, aqueles que, em função de reunir predicados que os qualificam a entender e avaliar os benefícios da qualidade informacional contábil, exerceriam efetiva demanda por conservadorismo condicional e por outras características qualitativas da informação contábil.

$\mathrm{Na}$ presença da demanda de investidores sofisticados, gestores reportariam lucros conservadores - condicionais à existência de bad news, sinalizando sobre a situação econômica da firma no que tange aos fluxos de caixa esperados no futuro; tal informação equivale aos argumentos utilizados na explicação de custo de capital como direcionador de políticas de financiamento da firma, como sugerido nos conceitos tratados por Ross (1977), Leland e Pyle (1977), Myers (1984) e Myers e Majluf (1984).

A literatura sobre demanda informacional de investidores sofisticados como direcionadora de conservadorismo condicional tem apresentado evidências que apontam tanto para relação positiva no comportamento de tais variáveis (Moghaddam, Amirzadeh \& Heidari, 2013) quanto negativa (Chi, Liu \& Wang, 2009), utilizando investidores institucionais como proxy para representar tal sofisticação.

Tais pesquisas mostram, contudo, limitação na delimitação de representantes de investidores sofisticados, pois consideram as entidades de investidores institucionais como conceito universal, não reconhecendo que a demanda por conservadorismo condicional pode variar entre diferentes categorias de investidores institucionais, segundo interesses de seus cotistas e fornecedores de recursos, conforme Ramalingegowda e Yu (2012).

Ramalingegowda e Yu (2012) e Chen et al. (2015) legitimam tal limitação, evidenciando que diferentes categorias de investidores institucionais afetam de forma desigual a prática do conservadorismo condicional nas firmas.

No contexto brasileiro, em busca não exaustiva, os estudos não se concentraram em tal direcionamento; todavia, há evidências empíricas que apontam para ausência da prática de 
conservadorismo condicional nos lucros divulgados (Coelho \& Lima, 2007; Paulo, Martins \& Girão, 2014). De acordo com Coelho, Galdi e Lopes (2017), o ambiente institucional brasileiro de financiamento das firmas não encoraja gestores a sinalizações por meio da divulgação contábil com qualidade superior, embora se deva ressaltar que a necessidade por fundos poderia incentivar esses gestores a aprimorar o processo de sinalização da situação econômica para investidores e demais stakeholders.

A força da demanda informacional de investidores institucionais pode se constituir em incentivo econômico ao comportamento de gestores no Brasil, no sentido de influenciá-los a reportar agregados contábeis que sinalizem perspectivas para projeção de fluxos esperados de caixa, a partir de sinais informacionais eficientes e confiáveis, para suas decisões de fornecer recursos a custos de capital satisfatórios.

Sob tal contexto, busca-se coletar evidências que responda a seguinte questão: em que medida a demanda informacional de categorias distintas de investidores institucionais influencia a decisão de gestores no Brasil a adotar o conservadorismo condicional no sentido de sinalizar sobre a situação econômica das firmas?

Demanda informacional de categorias diversas de investidores institucionais foi representada pela participação de Fundos de Pensão e de Investimentos, Instituições Financeiras, Seguradoras e Administradores de Carteiras na base acionária das firmas e em seus órgãos diretivos e o conservadorismo condicional foi estimado segundo Ball e Shivakumar (2005). Já a sinalização de gestores no sentido de captar recursos de investidores sofisticados se especifica pelo maior nível de qualidade informacional (representada pelo conservadorismo condicional) associado à presença daqueles investidores na estrutura acionária e diretiva das firmas.

$\mathrm{O}$ estudo se mostra relevante no sentido de captar efeito pouco documentado no contexto brasileiro, qual seja, a influência de demanda informacional de investidores sofisticados, exógenos à administração da firma, na decisão de seus gestores em sinalizar lucros contábeis informacionalmente eficientes; tal sinalização se expressa prelo reconhecimento tempestivo assimétrico de perdas (ALRT), fonte do conservadorismo condicional (CC). Esses investidores têm sido caracterizados em outros mercados por compreender os benefícios informacionais do conservadorismo condicional, exercendo demanda efetiva por tal atributo, conforme Ramalingegowda e Yu (2012). Não se conhecia de forma clara, no contexto brasileiro, se esse tipo de investidor, representado por fundos, carteiras e intermediários financeiros (os investidores institucionais) exercia demanda significante junto a gestores de firmas por tal atributo que sinaliza os efeitos econômicos captados pela contabilidade. Tal lacuna se pretende preencher nesta pesquisa, aclarando se o fato de ser conhecedor do método contábil e de ser administrador de recursos de forma profissional - gerenciando recursos de terceiros contribui para sinalização de maior qualidade nas demonstrações contábeis das firmas.

Ademais, como Collins, Gong e Hribar (2003) assinalaram que a demanda informacional de investidores institucionais varia entre suas categorias (fundos, administradores de carteira, instituições financeiras) examinam-se evidências sobre as categorias que mais afetam a demanda por conteúdo da informação contábil, em outras palavras, se há diferenciação na necessidade por tais informações; neste sentido, se faz referência a estudos que buscam captar demanda por conservadorismo condicional, incluindo categorias ainda não incluídas no rol desses testes, na motivação de categorias de investidores institucionais no contexto brasileiro, em face de sua especialização em estratégias de investimento.

Embora Ramalingegowda e Yu (2012) e Chen et al. (2015) tenham apresentado evidências sobre interesses diversos por informação contábil, exercidos por diferentes categorias de investidores institucionais, tais pesquisas classificaram as categorias com base em Bushee (2001), não aplicável no contexto brasileiro em função da indisponibilidade de dados. Alternativamente, emprega-se investidores institucionais com presumíveis estratégias diferenciadas, tornando exequível a pesquisa no contexto brasileiro. Tal abordagem alternativa inova, mesmo no contexto internacional, quanto ao 
uso de classificações de investidores institucionais, diferenciadas em relação a Bushee (2001), para capturar a demanda por conservadorismo condicional.

O estudo avança, ainda, por fornecer indícios complementares de que, mesmo em países com ambiente institucional com baixos incentivos econômicos à qualidade informacional contábil, o reporte de lucros contábeis com indícios de conservadorismo condicional atende à demanda informacional de investidores.

No contexto nacional, a pesquisa contribui para maior entendimento do impacto diferenciado de distintas categorias de investidores institucionais em atributos que refletem qualidade da informação contábil, abrindo espaço para futuras pesquisas que empreendam investigação no sentido de desvendar as causas dos comportamentos diferenciados dessas categorias ora tratadas.

\section{REFERENCIAL TEÓRICO E DESENVOLVIMENTO DA HIPÓTESE}

No modelo contratual da firma, gestores são os agentes detentores de maior nível de informações sobre a firma em face dos seus demais agentes contratantes, evento que caracteriza o que se conhece por assimetria informacional. Na presença de assimetria informacional, agentes detentores de informações privadas poderão tomar melhores decisões que outros agentes que não a possuem (Connelly et al., 2011).

A sinalização de informações ao mercado por parte das firmas tem sido apontada como atributo capaz de reduzir a assimetria informacional entre gestores e demais agentes contratantes com a firma, conforme Spence (1973). Segundo Spence (2002), o modelo de sinalização preocupa-se fundamentalmente com a redução de assimetria informacional entre partes contratantes, pelo qual uma das partes fornece sinais informacionais acerca de sua qualidade; tal evento reduziria custos de transação, tais como seleção adversa e risco moral (Akerloff, 1970), contribuindo para os negócios em qualquer mercado.

Com suporte em Spence $(1973,2002)$, os gestores reportam lucros com eficiência informacional, aqui identificada pela prática de conservadorismo condicional, como sinalizadores da qualidade da situação econômica da firma, o que favoreceria a tomada de decisão de investidores, demandantes de tais dados, quanto ao preço e retorno esperados dos títulos emitidos pela firma.

O conservadorismo condicional, neste contexto, representaria o sinal de qualidade da informação contábil (Connelly et al., 2011). A este respeito, Ball e Shivakumar (2005) argumentam que o conservadorismo condicional é importante atributo da qualidade das demonstrações contábeis, uma vez que incrementa a utilidade dessas demonstrações para investidores, credores, gestores e todas as outras partes contratantes com a firma.

Tal decisão dos gestores, de outra parte, seria incentivada por força da demanda informacional de usuários das informações contábeis, conforme Watts (2003). Ball e Shivakumar (2005) e Watts (2003) apontam investidores como efetivos demandantes do conservadorismo condicional, os quais exerceriam por meio deste atributo mecanismos de governança no sentido de lhes prover informações que transmitiriam o sentido de precaução dos gestores no sentido de resguardar futuros choques na liquidez da firma em face de fatos adversos atuais, as más notícias.

Argumentam os autores que tal postura tende a apurar a eficiência contratual do ponto de vista econômico, eis que a prática do conservadorismo condicional anteciparia o registro de efeitos econômicos sobre o valor da firma; o conservadorismo condicional transmite maior proteção aos interesses desses stakeholders, uma vez que evidencia que gestores estejam menos propensos a investir em projetos que, ex ante, indicam VPL negativo provável, e a continuar em investimentos com fluxos de caixa negativos, ex post, segundo Ball e Shivakumar (2005).

Ademais, supriria, segundo Francis et al. (2004), a dependência de investidores por sinais informacionais eficientes, de maior qualidade. Também se nota que sinais informacionais de maior qualidade contribuem para redução da assimetria informacional entre investidores e gestores. 
Ball e Shivakumar (2005) apresentaram evidências, no contexto do Reino Unido, que reforçam o argumento de que a prática do conservadorismo condicional é dependente da demanda informacional de usuários das informações contábeis; no contexto brasileiro, Coelho e Lima (2007) apresentaram evidências de que tal demanda manifestava-se incipiente no sentido de promover incentivos econômicos ao comportamento de gestores no sentido de ofertarem demonstrações contábeis de maior eficiência informacional.

Nem todo investidor, de outra parte, estará habilitado a exercer demanda efetiva por conservadorismo condicional, conforme argumentam Ramalingegowda e Yu (2012); argumentam com a existência de classes de investidores sofisticados e não sofisticados, apontando que é menos provável que a classe de investidores não sofisticados avalie se firmas utilizam consistentemente o conservadorismo em seus reportes financeiros, uma vez que esses investidores tendem a negociar no mercado de capitais baseando-se em insights comportamentais.

Investidores sofisticados, segundo Ramalingegowda e Yu (2012), teriam maior capacidade de avaliar os benefícios da prática do conservadorismo condicional na divulgação dos relatórios financeiros quando comparados a investidores não sofisticados e, portanto, poderiam exercer demanda efetiva por demonstrações contábeis preparadas sob a prática do conservadorismo condicional. A força da demanda de investidores sofisticados poderá, portanto, se constituir em incentivo à decisão de gestores em reportar lucros sob a prática do conservadorismo condicional.

Ademais, com suporte em Gupta, Govindarajan e Malhotra (1999) e Gulati e Higgins (2003), a maior capacidade de investidores sofisticados em entender os benefícios informacionais do conservadorismo condicional funcionaria como feedback a gestores no sentido de empreender relatórios contábeis úteis e informativos, dado que os sinalizadores estariam interessados sobre as demandas dos receptores, no caso, usuários da informação contábil, para decidir sobre sinais mais confiáveis; receptores mais atentos a sinais; capacidade de interpretação dos receptores e como estes estarão interpretando os sinais, seguindo o esquema desenhado em Connelly et al. (2011).

Pesquisas sobre a influência da demanda informacional de investidores sofisticados na prática do conservadorismo condicional por parte de gestores de firmas têm apresentado resultados tanto de influência positiva (Moghaddam, Amirzadeh \& Heidari, 2013) quanto de influência negativa (Chi, Liu \& Wang, 2009).

Moghaddam, Amirzadeh e Heidari (2013) examinaram a relação entre prática de conservadorismo condicional e a atuação de investidores sofisticados no contexto do mercado de capitais do Irã no período 2001-2010. Além disso, empreenderam testes considerando a separação de investidores sofisticados segundo diferentes formulações de participações destes investidores nas firmas; sua atuação foi considerada por participação mais ou menos ativa nas decisões dos gestores das firmas. O conservadorismo condicional foi estimado utilizando-se os modelos desenvolvidos por Ball e Shivakumar (2005) e Givoly e Hain (2000). A participação de investidores sofisticados foi mensurada pela participação acionária total de investidores institucionais e pela presença desses investidores em órgãos diretivos das firmas; nesta última formulação, investidores institucionais são separados em dois grupos: (1) Investidores Institucionais Ativos, os quais participam de órgãos diretivos das firmas; (2) Investidores Institucionais Passivos, os quais não participam daqueles órgãos. Os achados sinalizaram que a participação acionária e em órgãos diretivos de investidores sofisticados relacionam-se positivamente à prática do conservadorismo condicional segundo os dois modelos.

Já Chi, Liu e Wang (2009) examinaram tal relação no contexto do mercado de capitais de Taiwan no período 1996-2004. A prática do conservadorismo condicional foi estimada pelo modelo desenvolvido por Khan e Watts (2009). Já a participação de investidores sofisticados foi mensurada pelo percentual de participação acionária de investidores institucionais. Os achados apontaram para relação negativa entre conservadorismo condicional e participação de investidores sofisticados, sugerindo que estes não influenciam os gestores a divulgar demonstrações financeiras com conservadorismo condicional. 
Convém destacar que tais pesquisas sofrem de relevante limitação, uma vez que consideram investidores institucionais como representantes eficientes da classe de investidores sofisticados, mas considerando aqueles investidores como categoria homogênea. Tal fato fragiliza os resultados evidenciados, dada a existência de diferentes categorias de investidores institucionais com comprovada heterogeneidade (Davis \& Steil, 2001).

Ademais, Ramalingegowda e Yu (2012) afirmam que a demanda de investidores institucionais por conservadorismo condicional provavelmente variará entre as categorias, segundo os interesses de seus cotistas e fornecedores de recursos; apontam os autores atributos de investidores institucionais, já evidenciados na literatura, tais como longo horizonte temporal para o termo do investimento (Bushee, 1998; Chen, Harford, \& Li, 2007; Gaspar, Massa, \& Matos, 2005); concentração acionária (Brickle, Lease, \& Smith, 1988; Chen, Harford, \& Li, 2007); e independência da gestão (Chen, Harford, \& Li, 2007), como características que induzem a maior incentivo aos gestores para qualidade informacional.

Bushee (1998) e Velury e Jenkins (2006) apontam, ainda, que investidores institucionais não apenas são sofisticados em utilizar e entender a informação contábil, mas também capazes de monitorar e influenciar o comportamento dos gestores, no sentido de desencorajá-los a tomar decisões com interesses diversos.

Categorias de investidores institucionais com tais atributos, conforme Ramalingegowda e $\mathrm{Yu}$ (2012), seriam aquelas que provavelmente apresentariam efetiva demanda por conservadorismo condicional, dado que visualizariam tal atributo como mecanismo de governança.

Os autores investigaram a hipótese, considerando amostra de firmas americanas no período 1995-2006. A medida de conservadorismo condicional foi estimada a partir de Basu (1997). Participação de investidores institucionais foi estimada seguindo as etapas a seguir: (i) classificação de investidores institucionais em dedicados, quase-indexados e transientes, baseando-se na rotatividade e na diversificação de seus portfolios, conforme proposto em Bushee (2001), para identificar aqueles com longo horizonte temporal de investimentos e com concentração acionária; (ii) classificação, conforme Brickley, Lease e Smith (1988), de companhias de investimentos; administradores independentes de investimentos; e fundos de pensão públicos, como investidores com gestão independente, sendo os demais tipos tratados com não independentes; (iii) denominação de investidor institucional monitor para aqueles classificados concomitantemente como dedicados e com gestão independente. A participação de investidores institucionais monitores, endogenamente determinada por características das firmas, foi regredida em função de outras características das firmas (tamanho, ambiente informacional, oportunidades de investimentos, idade da firma, etc.) tentando explicar aquela participação, seguindo Lafond e Roychowdhury (2008); os resíduos da regressão foram utilizados como medida da participação residual de investidores institucionais monitores. Os achados sinalizaram que investidores institucionais monitores influenciam a decisão de gestores na preparação de demonstrações financeiras que apresentavam maior grau de conservadorismo condicional.

Chen et al. (2015) examinaram se investidores institucionais com longos horizontes temporais de investimento demandam demonstrações contábeis com maior grau de conservadorismo condicional no ambiente chinês, no período 2008-2011. Conservadorismo condicional foi estimado segundo Khan e Watts (2009). Horizonte temporal de investimentos foi estimado de acordo com a rotatividade do portfólio de negociação de cada investidor institucional; estimou-se medida que captura o horizonte de investimento de todos os investidores institucionais participantes de uma firma particular em dado ano, sendo tal medida denominada rotatividade do investimento institucional e representativa do horizonte temporal de investimento de investidores institucionais. Os achados sinalizaram que investidores institucionais com maiores horizontes temporais de investimentos associam-se à divulgação de demonstrações contábeis menos conservadoras. Argumentam os autores que a diferença entre seus resultados e os achados de Ramalingegowda e Yu (2012) pode ser explicada 
em função do conjunto de regulações no mercado de capitais chinês, o qual pode ter criado incentivos para a demanda por demonstrações contábeis com menor grau de conservadorismo condicional.

No contexto brasileiro, estudos com tal direcionamento específico não foram identificados, destacando-se que pesquisas no ambiente brasileiro têm evidenciado que gestores de firmas tendem a divulgar lucros com qualidade inferior, inclusive pela ausência de sinais de conservadorismo condicional nas demonstrações contábeis divulgadas (Coelho, \& Lima, 2007; Paulo, Martins, \& Girão, 2014).

A força da demanda informacional de investidores institucionais, tidos como sofisticados, contudo, poderá se constituir em incentivo econômico ao comportamento de gestores, no Brasil, no sentido de que divulguem demonstrações contábeis de maior qualidade informacional, pela presença do atributo conservadorismo condicional.

Por todo o exposto, a influência de investidores institucionais na decisão de gestores em reportar demonstrações contábeis com maior eficiência informacional, no que diz respeito a decisões que antecipem reconhecimento de perdas econômicas de forma assimétrica, se daria em função da existência de investidores institucionais que eficientemente representem a classe de investidores sofisticados, os quais dependeriam de sinais informacionais eficientes e, portanto, exerceriam efetiva demanda por conservadorismo condicional, na premissa de que desta forma se incrementaria a eficiência informacional de agregados contábeis divulgados. Ademais, gestores reportariam lucros sob a prática do conservadorismo condicional como sinal de maior qualidade informacional fornecida a seus usuários, atendendo, portanto, à demanda de investidores institucionais.

Considerando que a demanda por conservadorismo condicional obedece a necessidades informacionais geradas pelo processo decisório diferenciado das distintas categorias de investidores institucionais, conforme Ramalingegowda e Yu (2012), os testes focaram na participação explícita de fundos de pensão, fundos de investimento, seguradoras, instituições financeiras e administradores de carteiras, buscando-se captar o impacto da demanda informacional destes agentes na decisão de gestores em sinalizar a situação econômica da firma, por meio da prática de conservadorismo condicional no reconhecimento e mensuração de seus lucros.

Com base em tal argumentação, adota-se a hipótese de que a demanda informacional de categorias distintas de investidores institucionais influencia diferentemente a decisão de gestores em adotar conservadorismo condicional no reporte de lucros contábeis como sinal da qualidade da situação econômica de suas firmas.

Espera-se efeito diferenciado segundo a categoria de investidor institucional em função do argumento de que nem todas essas categorias de investidores teriam como útil o atributo do conservadorismo condicional e, portanto, estes não se constituiriam em demandantes efetivos por aquele atributo informacional. Assim, pela sinalização dos gestores, seriam atraídas como investidores as categorias cuja eficiência dependesse da análise fundamentalista das firmas, por meio das informações contábeis em suas decisões de investimento.

\section{PROCEDIMENTOS METODOLÓGICOS}

A população objeto da pesquisa reuniu sociedades por ação de capital aberto em funcionamento no Brasil com ações listadas na B3; a investigação compreendeu o período de 1998 a 2015, referenciando 453 firmas, totalizando 8.154 observações-ano.

A escolha do período de análise, conforme exposto acima, levou em consideração captar possíveis efeitos oriundos do aumento da participação de investidores institucionais na América Latina, principalmente entre os anos de 2002 e 2010, conforme destacado por Portugal (2010). Ademais, estende-se o período de análise coberto pelos estudos de Coelho e Lima (2007) e Paulo, Martins e Girão (2014), os quais sinalizaram ausência do atributo conservadorismo condicional no mercado de capitais brasileiro no período 1995 - 2011. 
A amostra final constitui-se de 361 empresas (4.408 observações-ano) após exclusão de itens por ausência de dados e por pertencerem ao setor financeiro, cujo sistema contábil difere da prática usual de firmas dos demais setores (Pincus, Rajgopal, \& Venkatachalam, 2007).

De modo a mitigar efeitos de outliers, processou-se winsorização dos dados, considerando percentis 5 e 95, seguindo Barth, Landsman e Lang (2008) e Liu e Skerrat (2014). A referida técnica compreende procedimento, no qual registros com valores abaixo ou acima de determinados limites (inferiores e superiores) são substituídos pelo valor apontado nesses limites estabelecidos, conforme destacam Sarlo Neto, Bassi e Almeida (2011).

Os dados foram coletados na base Economática ${ }^{\circledR}$; nos Formulários de Referência (FR) e nas Informações Anuais (IAN) e nas atas de Assembleia Geral Ordinária (AGO) e de Assembleia Geral Extraordinária (AGE), disponíveis nos sites da B3 e da CVM (DIVEXT), neste caso acessados pelo software SInC (Sistema de Informações Corporativas).

Participação de investidores institucionais na base acionária das firmas foi mensurada pela presença de distintas categorias desses investidores e por sua participação relevante no quadro societário das firmas.

Participação acionária relevante foi estimada considerando o investidor que detém parcela igual ou superior a 5\% de uma mesma classe ou espécie de ação; tal marco é sugerido como limite mínimo pela Comissão de Valores Mobiliários (2009) para efeitos de divulgação e de detalhamento de participação individual, conforme Instrução 480 de 7.12.2009.

Já participação em órgãos diretivos da firma foi mensurada considerando presença de representantes eleitos naqueles órgãos. Em todas essas formulações foram utilizadas variáveis dicotômicas para designar a presença das diferentes categorias de investidores institucionais segundo o critério de participação.

Categorias de investidores institucionais, nesta pesquisa, compreendem fundos de pensão, fundos de investimento, seguradoras, instituições financeiras e administradores de carteiras.

O exame da hipótese seguiu Ball e Shivakumar (2005), captando-se a antecipação tempestiva assimétrica de perdas esperadas com base em más notícias contemporâneas; por meio de accruals se registram de forma oportuna ganhos e perdas econômicas, pelos quais se antecipam fluxos de caixa esperados dados os fluxos de caixa realizados.

Ball e Shivakumar (2005) argumentam que o tratamento assimétrico entre o reconhecimento de ganhos e perdas econômicas se dá porque perdas econômicas são mais prováveis a serem reconhecidas em uma base temporal, com registro de tais perdas contra o lucro do período; ganhos econômicos, por sua vez, são mais prováveis de serem reconhecidos quando realizados, consequentemente contabilizados em uma base de caixa.

Essa assimetria, conforme Ball e Shivakumar (2005), implica em que a correlação entre fluxos de caixa e accruals seja maior no caso de antecipação de perdas econômicas. Os autores estimaram o modelo (1) segmentando as amostras em firmas que tenham apresentado fluxos de caixa negativos ou positivos no período.

Sob a hipótese de que firmas que experimentam a ocorrência de fluxos de caixa negativos tendem a antecipar tempestivamente o registro de perdas econômicas associadas ao evento com impacto no caixa, espera-se que o coeficiente $\beta_{3}$ seja positivo e maior que o coeficiente $\beta_{2}$; capta-se, ainda, a presença do conservadorismo condicional se $\beta_{3}+\beta_{2}>\beta_{2}$.

Para captar o efeito da participação de investidores institucionais no grau de conservadorismo condicional adotado pelas firmas, desenvolveu-se a regressão (1), conforme Coelho (2007), Coelho e Lima (2008) e Marques, Holanda e Coelho (2012):

$$
\begin{gathered}
A C C_{t}=\beta_{0}+\beta_{1} D F C_{t}+\beta_{2} F C_{t}+\beta_{3} D F C_{t} * F C_{t}+\beta_{4} P I I_{t}+\beta_{5} P I I_{t} * D F C_{t}+\beta_{6} P I I_{t} * F C_{t} \\
+\beta_{7} P I I_{t} * D F C_{t} * F C_{t}+\beta_{8} I F R S+\varepsilon_{t}
\end{gathered}
$$




\section{Em que:}

$A C C_{t}=$ Accruals do período $t$, escalados pelo ativo total de $t-1$;

$D F C_{t}=$ Dummy assumindo 1 para fluxos de caixas operacionais negativos e 0 , caso contrário;

$F C_{t}=$ Fluxo de caixa operacional no período $t$, escalado pelo ativo total de $t$ - 1 ;

$D F C_{t} * F C_{t}=$ Variável de interação para valores negativos de $\mathrm{FC}_{\mathrm{t}}$;

$\mathrm{PII}_{\mathrm{t}}=$ Dummy para tipo de participação ou para tipo de investidor; 1 para presença e 0 , caso contrário;

$P I I_{t} * D F C_{t}=$ Dummy captadora de impacto no intercepto do modelo;

$P I I_{t} * F C_{t}=$ Interação para valores positivos de $\mathrm{FC}_{\mathrm{t}}$ em firmas com presença de investidores institucionais;

$P I I_{t} * D F C_{t} * F C_{t}=$ interação para valores negativos de $\mathrm{FC}_{\mathrm{t}}$ em firmas com presença de investidores institucionais;

$I F R S=$ Dummy para períodos com padrão IFRS, que assume 1 se $t$ maior que 2009, e 0 em caso contrário;

$\varepsilon_{t}=$ termo de erro do modelo.

Accruals do período foram estimados tendo como proxy a variação da Necessidade de Capital de Giro (NCG), seguindo Dechow e Dichev (2002), conforme se expressa na equação (2):

$$
A C C_{t}=\left[\left(\Delta A C_{t}-\Delta A F_{t}\right)-\left(\Delta P C_{t}-\Delta P F_{t}\right)\right] / A T_{t-1}
$$

Em que:

$\mathrm{ACC}_{\mathrm{t}}=$ Accruals escalados pelo ativo total de $t-1$;

$\left(\triangle A C_{t}-\triangle A F_{t}\right)=$ incremento dos Ativos Circulantes Operacionais no período;

$\left(\triangle P C_{t}-\triangle P F_{t}\right)=$ incremento nos Passivos Circulantes Operacionais no período;

$A T_{t-1}=$ Ativo Total no período $t-1$.

Os fluxos de caixa operacional foram obtidos pela diferença entre Lucros Antes de Juros e Impostos sobre o lucro (LAJIR), escalado pelo ativo total de $t$-1, e accruals do período estimados conforme a equação (2).

De forma a se controlar possíveis efeitos advindos da mudança de padrão contábil, também se incluiu variável binária representativa do período após convergência ao padrão IFRS. A esse respeito, Ahmed, Neel e Wang (2013), investigando amostra de firmas para conjunto de vinte países, sinalizaram que a qualidade informacional da contabilidade decresceu após a adoção obrigatória do padrão IFRS por parte das firmas; especificamente para accruals, apontaram reporte mais agressivo deste componente do lucro divulgado.

Espera-se que o coeficiente incremental $\beta_{7}$ seja positivo e maior que o coeficiente $\beta_{3}$, na hipótese de reconhecimento superior tempestivo de perdas para as firmas com presença de investidores institucionais; de forma a se captar a presença de maior nível de conservadorismo condicional nestas empresas, espera-se que $\left(\beta_{2}+\beta_{3}+\beta_{6}+\beta_{7}\right)>\left(\beta_{2}+\beta_{3}\right)$, o que revelaria impacto marginal da presença de investidores institucionais na prática de conservadorismo condicional.

Detalham-se as variáveis do estudo no Quadro 1:

A estimação dos parâmetros dos modelos regressivos se deu por meio da análise de regressão linear múltipla com estimação pelo System Generalized Method of Moments (GMM-SYS), o qual proporciona maior eficiência, dada sua robustez de estimação na presença de endogeneidade e de auto correlação serial a partir da utilização de variáveis instrumentais sequencialmente exógenas (Barros et al., 2010).

Os modelos foram processados com correção de variância para amostras finitas, proposto por Windmeijer (2005), para correção da heterocedasticidade dos resíduos da regressão. Examinou-se, ainda, a existência de multicolinearidade entre as variáveis independentes a partir da análise de correlação e problemas de auto correlação dos resíduos por meio dos testes de Arellano e Bond (1991); tais problemas ausentes segundo os testes (não reportados). Investigou-se, ainda, pelo Hansen 
Test, que se apresentou não significante em todas as regressões, que os instrumentos utilizados na estimação são de fato exógenos, confirmando a eficiência de estimação por meio do GMM-SYS. Por fim, os resíduos não apresentaram distribuição normal, condição que não é crítica e pôde ser relaxada em função do tamanho da amostra, conforme Gujarati e Porter (2011), acerca da propriedade de estimadores com distribuição assintótica normal, à medida que a amostra aumenta de tamanho.

Quadro 1 - Sumário de informações das variáveis do estudo

\begin{tabular}{|c|c|c|c|}
\hline & \multicolumn{3}{|c|}{ Variável dependente } \\
\hline Variável & Descrição & Mensuração & Fonte \\
\hline \multirow[t]{2}{*}{$\mathrm{ACC}$} & Accruals do período & $\begin{array}{c}\text { Diferença entre o incremento dos Ativos } \\
\text { Circulantes Operacionais e o incremento nos } \\
\text { Passivos Circulantes Operacionais, conforme } \\
\text { relação (2) }\end{array}$ & $\begin{array}{c}\text { Adaptado de Coelho } \\
\text { (2007) }\end{array}$ \\
\hline & \multicolumn{3}{|c|}{ Variáveis independentes } \\
\hline Variável & Descrição & Mensuração & Fonte \\
\hline DFC & $\begin{array}{l}\text { Incidência de fluxos de } \\
\text { caixa negativos }\end{array}$ & $\begin{array}{l}\text { Dummy assumindo } 1 \text { para fluxos de caixas } \\
\text { operacionais negativos e } 0 \text {, caso contrário }\end{array}$ & $\begin{array}{l}\text { Ball e Shivakumar } \\
\text { (2005) }\end{array}$ \\
\hline $\mathrm{FC}$ & Fluxo de caixa operacional & (LAJIR/Ativo total em t-1) - ACC & $\begin{array}{l}\text { Adaptado de Dechow } \\
\text { e Dichev (2002) }\end{array}$ \\
\hline PII & $\begin{array}{c}\text { Participação de } \\
\text { investidores institucionais } \\
\text { nas firmas }\end{array}$ & $\begin{array}{c}\text { Captada por dummies para participação } \\
\text { acionária relevante e para presença em órgãos } \\
\text { diretivos de cada uma das categorias de } \\
\text { investidores institucionais }\end{array}$ & $\begin{array}{l}\text { Chen, Harford e Li } \\
\text { (2007) e Pucheta- } \\
\text { Martínez e García- } \\
\text { Meca (2014) }\end{array}$ \\
\hline IFRS & $\begin{array}{l}\text { Período de adoção do } \\
\text { padrão IFRS }\end{array}$ & $\begin{array}{l}\text { Dummy assumindo } 1 \text { para anos maiores que } \\
2009 \text { e } 0 \text {, caso contrário }\end{array}$ & $\begin{array}{l}\text { Telles e Salotti } \\
\text { (2015) }\end{array}$ \\
\hline
\end{tabular}

Fonte: elaboração própria.

Adicionalmente, fez-se descrição estatística das amostras segregadas segundo as diferentes categorias de investidores institucionais e diferentes formulações de participação desses investidores nas firmas, as quais se constituíram em segmentos específicos.

\section{RESULTADOS}

$\mathrm{Na}$ Tabela 1, apresenta-se frequência de firmas com participação de investidores institucionais, onde se destaca o significativo índice de sua presença em cerca de $71 \%$ das empresas do mercado de capitais do Brasil, com relevante participação em 36\% delas. Já a representação desses minoritários em órgãos diretivos das empresas alcança 10\% delas. Ressalta a proeminência destes recursos administrados na composição do financiamento das empresas, evidência já destacada em Gillan e Starks (2000) e Crisóstomo e González (2006); aponta, ainda, para baixa preocupação com a gestão de tais participações, mercê da baixa relação representação/capital relevante.

Tabela 1 - Frequência de Firmas com Participações de Investidores Institucionais (\%)

\begin{tabular}{lcc}
\multicolumn{1}{c}{ Tipo de Participação } & Acionária & Em órgãos diretivos \\
\hline Completa & 70,7 & 9,5 \\
Acionária Relevante & 35,8 & - \\
a. Fundos de Pensão & 12,0 & 9,5 \\
b. Fundos de Investimento & 16,6 & 4,8 \\
c. Instituições Financeiras & 14,2 & 5,3 \\
d. Seguradoras & 2,5 & 2,1 \\
e. Administradores de Carteira & 16,1 & 0,1 \\
\hline
\end{tabular}

Fonte: dados da pesquisa.

Em relação às diferentes categorias de investidores institucionais, sobressaem Fundos de Investimento e Instituições Financeiras com maior participação em firmas tanto considerando participação acionária relevante quanto presença em órgãos diretivos; provavelmente influencia tal 
situação a captação de clientes e a forte negociação de seus títulos, em função da movimentação de cotas dos fundos; como os mesmos são administrados por instituições financeiras, os interesses confluem para o comportamento identificado.

Fundos de Pensão tanto mantêm participação relevante quanto na gestão de empresas dado o caráter de longo prazo de seu relacionamento com o mercado. Administradores de Carteiras representam a segunda categoria de maior participação acionária relevante, o que não é refletido na relação com as firmas, possivelmente dado seu caráter mais especulativo.

Pelo exposto, afora Seguradoras, as demais categorias de investidores institucionais teriam maiores incentivos para monitorar gestores, no sentido de fornecimento de demonstrações financeiras úteis e relevantes segundo a presença do conservadorismo condicional.

Pela Tabela 2, nota-se que os accruals (ACC) são fracamente diferenciados entre firmas com e sem participação acionária relevante de investidores institucionais (ao nível de 6\%), o que não ocorre quanto à participação em órgãos diretivos; salienta-se a elevada variabilidade destes atributos.

Tabela 2 - Descrição das amostras e variáveis

\begin{tabular}{|c|c|c|c|c|c|c|}
\hline \multirow{3}{*}{ Grupos } & & \multirow{3}{*}{$\mathrm{N}$} & \multicolumn{4}{|c|}{ Variáveis } \\
\hline & & & \multicolumn{2}{|r|}{$\mathrm{ACC}$} & \multicolumn{2}{|r|}{$\mathrm{FC}$} \\
\hline & & & Média & Desvio-padrão & Média & Desvio-padrão \\
\hline \multirow{2}{*}{ Participação acionária relevante } & Não & 2.829 & $-0,00$ & 0,09 & 0,04 & 0,16 \\
\hline & Sim & 1.579 & 0,00 & 0,08 & 0,04 & 0,16 \\
\hline \multicolumn{3}{|c|}{ Mann-Whitney ( $p$-value) } & \multicolumn{2}{|r|}{0,06} & \multicolumn{2}{|r|}{0,36} \\
\hline \multirow{2}{*}{ Participação em órgãos diretivos } & Não & 4.001 & 0,00 & 0,09 & 0,04 & 0,16 \\
\hline & Sim & 407 & 0,00 & 0,07 & 0,08 & 0,13 \\
\hline \multicolumn{3}{|c|}{ Mann-Whitney ( $p$-value) } & \multicolumn{2}{|r|}{0,99} & \multicolumn{2}{|r|}{0,00} \\
\hline
\end{tabular}

Nota: Observações-ano: 4.408.

Fonte: dados da pesquisa.

Quanto ao fluxo de caixa operacional, não se detectam diferenças em relação aos dois grupos quanto à participação acionária relevante, mantendo-se o padrão de alta variabilidade entre firmas na amostra total, sendo diferenciado o comportamento quando se isolam as firmas com presença de investidores institucionais em órgãos diretivos, com menor variabilidade para os dados referentes a firmas com presença de investidores neste quesito.

$\mathrm{Na}$ estimação das regressões, foram identificadas como endógenas as variáveis accruals (ACC) e fluxo de caixa operacional (FC), utilizando-se, então, a segunda defasagem dessas variáveis como instrumento. As demais variáveis, consoante indicado pelos testes, foram tratadas como exógenas, inclusive aquelas de interação com o fluxo de caixa (FC).

$\mathrm{Na}$ Tabela 3 se apresentam os resultados com relação ao conjunto da amostra, envolvendo todos os investidores institucionais arrolados na amostra. Nesta e nas demais tabelas se mostram os efeitos isolados para as interações de participação pesquisadas.

As evidências apontam coeficiente $\beta_{3}$ negativo para todas as formulações, indicando que o conjunto de empresas da amostra não adota reconhecimento tempestivo assimétrico de perdas econômicas na presença de más notícias (fluxos de caixa operacional contemporâneos negativos), adotando, por outro lado, práticas de antecipação de ganhos, dada a evidência do coeficiente $\beta_{2}$ positivo, independente dos sinais do fluxo de caixa operacional.

Esses achados se apresentam em linha com Coelho e Lima (2007) e Paulo, Martins e Girão (2014), que apontaram indícios de que firmas, no Brasil, não praticariam o conservadorismo condicional em seus reportes de lucros.

A participação de investidores institucionais altera tal comportamento nas três primeiras formulações, vez que o coeficiente $\beta_{7}$ mostra-se positivo, conforme esperado, alterando-se também o comportamento do coeficiente $\beta_{6}$ em relação àquele do $\beta_{2}$; na hipótese de antecipação assimétrica de perdas, tais evidências sugerem que as participações relatadas alteram marginalmente $o$ 
comportamento de gestores quanto à informação sobre precauções com o resultado futuro da firma, antecipando de forma oportuna e assimétrica perdas futuras possíveis.

Tabela 3 - Investidores Institucionais: Conservadorismo Condicional

\begin{tabular}{|c|c|c|c|c|}
\hline \multirow[b]{2}{*}{ Coeficientes } & \multicolumn{4}{|c|}{ Participação de Investidores Institucionais } \\
\hline & Acionária & Acionária Relevante & $\begin{array}{l}\text { Em Órgãos } \\
\text { Diretivos }\end{array}$ & Interação $(*)$ \\
\hline $\mathrm{ACC} t-2$ & 0,00 & 0,01 & 0,02 & 0,02 \\
\hline$(\beta 1)$ & $0,15 * * *$ & $0,10 * * *$ & $0,07 * * *$ & $0,07 * * *$ \\
\hline$(\beta 2)$ & $1,06 * *$ & $0,51 * * *$ & $0,30 * * *$ & $0,29 * * *$ \\
\hline$(\beta 3)$ & $-1,21 * * *$ & $-0,70 * * *$ & $-0,46 * * *$ & $-0,44 * * *$ \\
\hline$(\beta 4)$ & $0,16 * * *$ & $0,11 * * *$ & $0,07 * * *$ & $0,07 * * *$ \\
\hline$(\beta 5)$ & $-0,14 * * *$ & $-0,09 * * *$ & $-0,06 * * *$ & $-0,06 * * *$ \\
\hline$(\beta 6)$ & $-1,42 * * *$ & $-0,87 * * *$ & $-0,59 * * *$ & $-0,59 * * *$ \\
\hline$(\beta 7)$ & $1,47 * * *$ & $1,01 * * *$ & $0,60 * * *$ & 0,37 \\
\hline IFRS & $-0,02 * * *$ & $-0,01 * * *$ & $-0,01 * * *$ & $-0,01 * * *$ \\
\hline INTERCEPTO & $-0,12 * * *$ & $-0,07 * * *$ & $-0,04 * * *$ & $-0,04 * * *$ \\
\hline$\beta 2+\beta 3$ & $-0,15$ & $-0,19$ & $-0,15$ & $-0,16$ \\
\hline$\beta 2+\beta 3+\beta 6+\beta 7$ & $-0,10$ & $-0,06$ & $-0,14$ & $-0,37$ \\
\hline Estat. Wald & $259,41 * * *$ & $243,94 * * *$ & $219,21 * * *$ & $203,13 * * *$ \\
\hline $\operatorname{AR}(1)$ & $-7,25 * * *$ & $-8,66 * * *$ & $-8,87 * * *$ & $-8,91 * * *$ \\
\hline $\operatorname{AR}(2)$ & $-0,63$ & 0,02 & $-0,05$ & 0,02 \\
\hline Hansen test & $46,12 *$ & 39,29 & 41,82 & 40,48 \\
\hline
\end{tabular}

Nota: Modelo: $A C C=\beta_{0}+\beta_{1} D F C_{t}+\beta_{2} F C_{t}+\beta_{3} D F C_{t} * F C_{t}+\beta_{4} P I I_{t}+\beta_{5} P I I_{t} * D F C_{t}+\beta_{6} P_{I I} * F C_{t}+\beta_{7} P I I_{t} *$ $D F C_{t} * F C_{t}+\beta_{8} I F R S+\varepsilon_{t}$.

Definição das variáveis: $\mathrm{ACC}=$ accruals correntes no período $t$ escalados pelo ativo total de $t-1 ; \mathrm{DFC}=d u m m y$ assumindo 1 para fluxos de caixas operacionais negativos e 0 em caso contrário; $\mathrm{FC}=$ fluxo de caixa operacional no período $t$ escalado pelo ativo total de $t-1 ; \mathrm{DFC} * \mathrm{FC}=$ interação para valores negativos de $\mathrm{FC}$; PII $=$ variável binária para investidores institucionais; 1 para presença e 0 , caso contrário; $\mathrm{PII} * \mathrm{DFC}=$ dummy captadora de impacto no intercepto do modelo; $\mathrm{PII} * \mathrm{FC}=$ interação para FC positivo na presença de investidores institucionais; PII*DFC*FC = interação para FC negativo na presença de investidores institucionais; IFRS = dummy para padrão IFRS, que assume 1 se t maior que 2009, e 0 caso contrário; $\varepsilon=$ termo de erro do modelo.

(*) Entre Participação Acionária Relevante e presença em Órgãos diretivos.

Observações-ano: 3.512. Número de instrumentos: 42.

* Significância ao nível de 10\%. ** Significância ao nível de 5\%. *** Significância ao nível de $1 \%$.

Fonte: dados da pesquisa.

Contudo, não se pode afirmar que a participação de tais investidores esteja associada à prática integral do conceito de conservadorismo condicional eis que, mesmo com $\left(\beta_{2}+\beta_{3}+\beta_{6}+\beta_{7}\right)>\left(\beta_{2}+\beta_{3}\right)$, os sinais negativos dos somatórios não estão previstos neste modelo de avaliação; também causa espécie, em relação aos preceitos do modelo a não significância dos coeficientes associados à interação entre participação acionária relevante e presença em órgãos diretivos, o que careceria de testes mais específicos.

Tais achados são consistentes com Moghaddam, Amirzadeh e Heidari (2013), evidenciando que a presença de investidores institucionais, tanto acionária quanto em órgãos diretivos, influencia gestores a antecipar reconhecimento de perdas econômicas nos lucros divulgados, também sem documentar a situação preconizada como de conservadorismo condicional.

$\mathrm{Na}$ Tabela 4, apresentam-se resultados para testes investigando impacto da participação acionária relevante de diferentes categorias de investidores institucionais no reconhecimento antecipado assimétrico de perdas e na prática de conservadorismo condicional, segmentando-se, portanto, os resultados da coluna 3 da Tabela 3.

Os achados confirmam o comportamento sinalizado para o conjunto de firmas da amostra, com os coeficientes $\beta_{2}$ e $\beta_{3}$ apontando para ausência de conservadorismo condicional em todos os segmentos; o reconhecimento tempestivo assimétrico de perdas passa a se configurar por categorias com presença acionária relevante, exceto para as firmas com participação de fundos de pensão, com 
fraca significância; as demais categorias de institucionais apresentam coeficientes $\beta_{6}$ e $\beta_{7}$ conforme o esperado.

Tabela 4 - Participação Acionária Relevante: Conservadorismo Condicional

\begin{tabular}{|c|c|c|c|c|c|}
\hline \multirow[b]{2}{*}{ Coeficientes } & \multicolumn{5}{|c|}{ Categorias de Investidores } \\
\hline & $\begin{array}{l}\text { Fundos de } \\
\text { Pensão }\end{array}$ & $\begin{array}{c}\text { Fundos de } \\
\text { Investimentos }\end{array}$ & $\begin{array}{l}\text { Instituições } \\
\text { Financeiras }\end{array}$ & Seguradoras & Adm. de Carteiras \\
\hline $\mathrm{ACC} \mathrm{t}-2$ & 0,02 & 0,02 & 0,02 & 0,02 & 0,01 \\
\hline$(\beta 1)$ & $0,07 * * *$ & $0,07 * * *$ & $0,08 * * *$ & $0,07 * * *$ & $0,08 * * *$ \\
\hline$(\beta 2)$ & $0,27 *$ & $0,31 * *$ & $0,31 * *$ & $0,22 *$ & $0,34 * *$ \\
\hline$(\beta 3)$ & $-0,41 * * *$ & $-0,49 * * *$ & $-0,46 * * *$ & $-0,39 * * *$ & $-0,5 * * *$ \\
\hline$(\beta 4)$ & $0,07 * * *$ & $0,07 * * *$ & $0,09 * * *$ & $0,06 * *$ & $0,09 * * *$ \\
\hline$(\beta 5)$ & $-0,08 * * *$ & $-0,05 * * *$ & $-0,08 * * *$ & $-0,05^{*}$ & $-0,08 * * *$ \\
\hline$(\beta 6)$ & $-0,53 * * *$ & $-0,62 * * *$ & $-0,69 * * *$ & $-0,51 * * *$ & $-0,77 * * *$ \\
\hline$(\beta 7)$ & $0,44 *$ & $0,74 * * *$ & $0,69 * * *$ & $0,77 * * *$ & $0,84 * * *$ \\
\hline IFRS & $-0,01 * * *$ & $-0,01 * * *$ & $-0,01 * * *$ & $-0,01 * * *$ & $-0,01 * * *$ \\
\hline INTERCEPTO & $-0,04 * *$ & $-0,05 * * *$ & $-0,05 * * *$ & $-0,04 * *$ & $-0,05 * * *$ \\
\hline$\beta 2+\beta 3$ & $-0,14$ & $-0,17$ & $-0,15$ & $-0,16$ & $-0,16$ \\
\hline$\beta 2+\beta 3+\beta 6+\beta 7$ & $-0,23$ & $-0,05$ & $-0,16$ & 0,09 & $-0,09$ \\
\hline Estat. Wald & $204,01 * * *$ & $200,23 * * *$ & $210,67 * * *$ & $207,62 * * *$ & $232,09 * * *$ \\
\hline $\mathrm{AR}(1)$ & $-9,00 * * *$ & $-8,94 * * *$ & $-8,93 * * *$ & $-9,11 * * *$ & $-8,87 * * *$ \\
\hline $\operatorname{AR}(2)$ & $-0,18$ & $-0,21$ & 0,53 & 0,18 & 0,29 \\
\hline Hansen test & 41,99 & $43,08 *$ & 39,54 & 41,05 & 41,36 \\
\hline
\end{tabular}

Nota: $\quad$ Modelo: $\quad A C C=\beta_{0}+\beta_{1} D F C_{t}+\beta_{2} F C_{t}+\beta_{3} D F C_{t} * F C_{t}+\beta_{4} P R I I_{t}+\beta_{5} P R I I_{t} * D F C_{t}+\beta_{6} P R I I_{t} * F C_{t}+$ $\beta_{7} P R I I_{t} * D F C_{t} * F C_{t}+\beta_{8} I F R S+\varepsilon_{t}$.

Definição das variáveis: $\mathrm{ACC}=$ accruals correntes no período $t$ escalados pelo ativo total de $t$ - 1 ; DFC $=d u m m y$ assumindo 1 para fluxos de caixas operacionais negativos e 0 em caso contrário; $\mathrm{FC}=$ fluxo de caixa operacional no período $t$ escalado pelo ativo total de $t-1$; DFC*FC $=$ interação para valores negativos de FC; PRII = variável binária para investidores institucionais com participação acionária relevante; 1 para presença e 0 , caso contrário; PRII*DFC = dummy captadora de impacto no intercepto do modelo; PRII*FC = interação para FC positivo na presença de investidores institucionais com participação acionária relevante; PRII*DFC*FC = interação para FC negativo na presença de investidores institucionais com participação acionária relevante; IFRS = dummy para padrão IFRS, que assume 1 se t maior que 2009, e 0 caso contrário; $\varepsilon=$ termo de erro do modelo.

Observações-ano: 3.473. Número de instrumentos: 42.

* Significância ao nível de 10\%. ** Significância ao nível de 5\%. *** Significância ao nível de $1 \%$.

Fonte: dados da pesquisa.

Já o conservadorismo condicional apenas se verifica para o conjunto de firmas com presença acionária relevante de Seguradoras $\left[\left(\beta_{2}+\beta_{3}+\beta_{6}+\beta_{7}\right)>\left(\beta_{2}+\beta_{3}\right)\right.$ e positivo]. As evidências indicam, portanto, que a presença acionária relevante de categorias específicas de investidores institucionais distingue as decisões dos gestores quanto ao reporte de lucros sob a prática do conservadorismo condicional.

Tal achado tem consonância com o argumento de que investidores institucionais com grandes participações no capital das firmas são capazes de influenciar a decisão de gestores, inclusive no sentido destes agentes divulgarem informações de maior qualidade, conforme Chen, Harford e Li (2007).

$\mathrm{Na}$ Tabela 5 se exibem os testes examinando o impacto da presença em órgãos diretivos das firmas de representantes de diferentes fundos no reconhecimento antecipado assimétrico de perdas e no conservadorismo condicional das firmas, segregando-se, portanto, o conteúdo da coluna 4 da Tabela 3.

Novamente, os coeficientes $\beta_{2}$ e $\beta_{3}$, apontando para ausência de conservadorismo condicional em todos os segmentos, mostram que diferenças somente poderão depender das diferentes categorias de investidores. Os coeficientes referentes a seguradoras não foram processados por motivos econométricos, não aprofundados, provavelmente pela inexistência de fluxos de caixa contemporâneos negativos nas empresas com tais firmas compondo suas direções. 
Tabela 5 - Presença em órgãos diretivos: Conservadorismo Condicional

\begin{tabular}{|c|c|c|c|c|c|}
\hline \multirow[b]{2}{*}{ Coeficientes } & \multicolumn{5}{|c|}{ Categorias de Investidores } \\
\hline & $\begin{array}{l}\text { Fundos de } \\
\text { Pensão }\end{array}$ & $\begin{array}{c}\text { Fundos de } \\
\text { Investimentos }\end{array}$ & $\begin{array}{l}\text { Instituições } \\
\text { Financeiras }\end{array}$ & Seguradoras & $\begin{array}{l}\text { Adm. de } \\
\text { Carteiras }\end{array}$ \\
\hline $\mathrm{ACC} t-2$ & 0,02 & 0,02 & 0,02 & 0,02 & 0,02 \\
\hline$(\beta 1)$ & $0,07 * * *$ & $0,07 * * *$ & $0,07 * * *$ & $0,07 * * *$ & $0,07 * * *$ \\
\hline$(\beta 2)$ & $0,26 * *$ & $0,29 * *$ & $0,22 *$ & $0,25^{* *}$ & $0,25 * *$ \\
\hline$(\beta 3)$ & $-0,42 * * *$ & $-0,44 * * *$ & $-0,39 * * *$ & $-0,41 * * *$ & $-0,41 * * *$ \\
\hline$(\beta 4)$ & $0,07 * * *$ & $0,06 * * *$ & $0,05 * * *$ & $-0,01$ & $0,05 * * *$ \\
\hline$(\beta 5)$ & $-0,04 *$ & $-0,05 * * *$ & $-0,03$ & Omitida & $-0,06 * *$ \\
\hline$(\beta 6)$ & $-0,53 * * *$ & $-0,56 * * *$ & $-0,43 * * *$ & $-0,07$ & $-0,46 * *$ \\
\hline$(\beta 7)$ & $1,14 * * *$ & 0,25 & $0,73 * * *$ & Omitida & 0,30 \\
\hline IFRS & $-0,01 * * *$ & $-0,01 * *$ & $-0,01 * * *$ & $-0,01 * *$ & $-0,01 * * *$ \\
\hline INTERCEPTO & $-0,04 * * *$ & $-0,04 * * *$ & $-0,03 * *$ & $-0,04 * * *$ & $-0,04 * * *$ \\
\hline$\beta 2+\beta 3$ & $-0,16$ & $-0,15$ & $-0,16$ & $-0,16$ & $-0,16$ \\
\hline$\beta 2+\beta 3+\beta 6+\beta 7$ & 0,45 & $-0,46$ & 0,14 & - & $-0,31$ \\
\hline Estat. Wald & $210,58 * * *$ & $259,19 * * *$ & $197,58 * * *$ & $203,61 * * *$ & $206,3 * * *$ \\
\hline $\operatorname{AR}(1)$ & $-9,03 * * *$ & $-8,91 * * *$ & $-8,95 * * *$ & $-9,04 * * *$ & $-9,08 * * *$ \\
\hline $\operatorname{AR}(2)$ & $-0,06$ & 0,30 & 0,02 & 0,17 & 0,18 \\
\hline Hansen test & $42,64 *$ & 36,84 & $44,4 *$ & 39,50 & 40,05 \\
\hline
\end{tabular}

Nota: $\quad$ Modelo: $\quad A C C_{t}=\beta_{0}+\beta_{1} D F C_{t}+\beta_{2} F C_{t}+\beta_{3} D F C_{t} * F C_{t}+\beta_{4} P_{I I O}+\beta_{5} P_{I I O} * D F C_{t}+\beta_{6} P_{I I O} * F C_{t}+$ $\beta_{7} P I I O_{t} * D F C_{t} * F C_{t}+\beta_{8} I F R S+\varepsilon_{t}$.

Definição das variáveis: $\mathrm{ACC}=$ accruals correntes no período $t$ escalados pelo ativo total de $t-1 ; \mathrm{DFC}=$ dummy assumindo 1 para fluxos de caixas operacionais negativos e 0 em caso contrário; $\mathrm{FC}=$ fluxo de caixa operacional no período $t$ escalado pelo ativo total de $t-1 ; \mathrm{DFC} * \mathrm{FC}=$ interação para valores negativos de $\mathrm{FC} ; \mathrm{PIIO}=$ variável binária para investidores institucionais com participação em órgãos diretivos; 1 para presença e 0 , caso contrário; $\mathrm{PIIO} * \mathrm{DFC}=$ dummy captadora de impacto no intercepto do modelo; $\mathrm{PIIO} * \mathrm{FC}=$ interação para FC positivo na presença de investidores institucionais com participação em órgãos diretivos; $\mathrm{PIIO} * \mathrm{DFC} * \mathrm{FC}=$ interação para $\mathrm{FC}$ negativo na presença de investidores institucionais com participação em órgãos diretivos; IFRS = dummy para padrão IFRS, que assume 1 se t maior que 2009, e 0 caso contrário; $\varepsilon=$ termo de erro do modelo.

Observações-ano: 3.512. Número de instrumentos: 42.

* Significância ao nível de 10\%. ** Significância ao nível de 5\%. *** Significância ao nível de $1 \%$.

Fonte: dados da pesquisa.

Constata-se que o reconhecimento tempestivo assimétrico de perdas está configurado em firmas com presença de Fundos de Pensão e de Instituições Financeiras em seus órgãos diretivos (coeficientes significantes $\beta_{6}$ negativos e $\beta_{7}$ positivos), o que não ocorre com firmas com presença de fundos de investimento em seus colegiados. Apenas nas empresas associadas a Fundos de Pensão e Instituições Financeiras se verifica o conservadorismo condicional $\left[\left(\beta_{2}+\beta_{3}+\beta_{6}+\beta_{7}\right)>\left(\beta_{2}+\beta_{3}\right)\right.$ e positivos].

Tais achados sugerem que a participação expressa pela presença de Fundos de Pensão e de Instituições Financeiras em órgãos diretivos das empresas, contribui para que gestores divulguem informações com atributos requeridos de qualidade informacional, no sentido de conservadorismo condicional.

Tais achados estão em linha com Pucheta-Martínez e García-Meca (2014), segundo os quais, investidores institucionais com presença em órgãos diretivos das firmas contribui para que gestores sinalizem informação contábil de maior qualidade.

Na Tabela 6 se expõem os resultados para o teste investigando o impacto da interação de participação acionária relevante e presença em órgãos diretivos segundo a categoria de investidor institucional no reconhecimento antecipado assimétrico de perdas e na prática do conservadorismo condicional (coluna 5 da Tabela 3 ).

Repete-se que os coeficientes $\beta_{2}$ e $\beta_{3}$, apontando para ausência de conservadorismo condicional em todos os segmentos, mostram que diferenças somente poderão depender das diferentes categorias de investidores. Nesta formulação não se processaram, por razões 
econométricas, os testes associando Seguradoras e Administradores de Carteiras, assumindo-se o mesmo fenômeno acima relatado quanto aos dados da Tabela 5.

Tabela 6 - Participação Interativa: Conservadorismo Condicional

\begin{tabular}{|c|c|c|c|c|c|}
\hline \multirow[b]{2}{*}{ Coeficientes } & \multicolumn{5}{|c|}{ Categorias de Investidores } \\
\hline & $\begin{array}{c}\text { Fundos de } \\
\text { Pensão }\end{array}$ & $\begin{array}{c}\text { Fundos de } \\
\text { Investimentos }\end{array}$ & $\begin{array}{l}\text { Instituições } \\
\text { Financeiras }\end{array}$ & Seguradoras & $\begin{array}{l}\text { Adm. de } \\
\text { Carteiras }\end{array}$ \\
\hline $\mathrm{ACC} t-2$ & 0,02 & 0,02 & 0,02 & 0,02 & 0,01 \\
\hline$(\beta 1)$ & $0,07 * * *$ & $0,07 * * *$ & $0,07 * * *$ & $0,07 * * *$ & $0,07 * * *$ \\
\hline$(\beta 2)$ & $0,24 *$ & $0,27 * *$ & $0,22 *$ & $0,25^{* *}$ & $0,26 * *$ \\
\hline$(\beta 3)$ & $-0,39 * * *$ & $-0,43 * * *$ & $-0,38 * * *$ & $-0,41 * * *$ & $-0,42 * * *$ \\
\hline$(\beta 4)$ & $0,07 * * *$ & $0,06 * * *$ & $0,06^{* * *}$ & Omitida & $0,08 * * *$ \\
\hline$(\beta 5)$ & $-0,03$ & $-0,03$ & $-0,07 * *$ & Omitida & Omitida \\
\hline$(\beta 6)$ & $-0,53 * * *$ & $-0,48 * *$ & $-0,42 * *$ & Omitida & $-0,82 * * *$ \\
\hline$(\beta 7)$ & $1,28 * * *$ & $0,73 * * *$ & 0,10 & Omitida & Omitida \\
\hline IFRS & $-0,01 * * *$ & $-0,01 * *$ & $-0,01 * * *$ & $-0,01 * *$ & $-0,01 * *$ \\
\hline INTERCEPTO & $-0,04 * *$ & $-0,04 * * *$ & $-0,04 * *$ & $-0,04 * * *$ & $-0,04 * * *$ \\
\hline$\beta 2+\beta 3$ & $-0,16$ & $-0,16$ & $-0,15$ & $-0,16$ & $-0,16$ \\
\hline$\beta 2+\beta 3+\beta 6+\beta 7$ & 0,59 & 0,09 & $-0,48$ & - & \\
\hline Número de instrumentos & 42,00 & 42,00 & 42,00 & 38,00 & 40,00 \\
\hline Estat. Wald & $212,43 * * *$ & $206,48 * * *$ & $199,19 * * *$ & $191,64 * * *$ & $202,49 * * *$ \\
\hline $\operatorname{AR}(1)$ & $-9,10 * * *$ & $-8,96 * * *$ & $-9,04 * * *$ & $-9,04 * * *$ & $-9,02 * * *$ \\
\hline $\operatorname{AR}(2)$ & $-0,08$ & 0,20 & 0,11 & 0,17 & 0,20 \\
\hline Hansen test & 42,23 & 38,63 & $44,07 *$ & 39,47 & 39,08 \\
\hline
\end{tabular}

Nota: $\quad$ Modelo: $\quad A C C_{t}=\beta_{0}+\beta_{1} D F C_{t}+\beta_{2} F C_{t}+\beta_{3} D F C_{t} * F C_{t}+\beta_{4} P_{R} I I_{t} * P I I O_{t}+\beta_{5} P_{R I I} * P I I O_{t} * D F C_{t}+$ $\beta_{6} P_{R I I} * P_{t} I I O_{t} * F C_{t}+\beta_{7} P R I I_{t} * P I I O_{t} * D F C_{t} * F C_{t}+\beta_{8} I F R S+\varepsilon_{t}$.

Definição das variáveis: $\mathrm{ACC}=$ accruals correntes no período $t$ escalados pelo ativo total de $t-1$; DFC $=$ dummy assumindo 1 para fluxos de caixas operacionais negativos e 0 em caso contrário; $\mathrm{FC}=$ fluxo de caixa operacional no período $t$ escalado pelo ativo total de $t-1 ; \mathrm{DFC} * \mathrm{FC}=$ interação para valores negativos de FC; PRII*PIIO = variável binária para presença de investidores institucionais com participação acionária relevante e presença em órgãos diretivos; 1 para presença e 0 , caso contrário; $\mathrm{PRII} * \mathrm{PIIO} * \mathrm{DFC}=$ dummy captadora de impacto no intercepto do modelo; PIIR*PIIO*FC = interação para FC positivo na presença de investidores institucionais com participação acionária relevante e presença em órgãos diretivos; PRII*PIIO*DFC*FC = interação para FC negativo na presença de investidores institucionais com participação acionária relevante e presença em órgãos diretivos; IFRS = dummy para padrão IFRS, que assume 1 se t maior que 2009, e 0 caso contrário; $\varepsilon=$ termo de erro do modelo.

Observações-ano: 3.512 .

* Significância ao nível de 10\%. ** Significância ao nível de 5\%.*** Significância ao nível de $1 \%$.

Fonte: dados da pesquisa.

Os resultados sinalizam, nesta formulação, que firmas com a participação interativa proposta praticam reconhecimento tempestivo assimétrico de perdas (coeficientes significantes $\beta_{6}$ negativos e $\beta_{7}$ positivos) e o conservadorismo condicional $\left[\left(\beta_{2}+\beta_{3}+\beta_{6}+\beta_{7}\right)>\left(\beta_{2}+\beta_{3}\right)\right.$ e positivos], no caso de Fundos de Pensão e de Fundos de Investimentos atuando como participantes, sem que as Instituições Financeiras desempenhem papel diferenciador neste caso.

Esses achados se apresentam em linha, novamente, com Chen, Harford e Li (2007) e PuchetaMartínez e García-Meca (2014), os quais apontaram tanto a participação acionária relevante quanto a presença em órgãos diretivos como atributos que contribuem para maior qualidade da informação contábil, tomadas separadamente. A interação dessas formulações de participação de investidores institucionais, conforme as evidências, parece também contribuir naquela direção de qualidade informacional.

Destaque-se a sinalização de impacto diferenciado da convergência ao IFRS em todos os modelos estimados, dado que o coeficiente $\beta_{8}$ se mostrou negativo e significante em todas as regressões, confirmando-se o impacto do padrão IFRS no reconhecimento de accruals, confirmandose o argumento de Ahmed, Neel e Wang (2013) sobre a relevância de considerar a mudança de padrão em modelos de accruals. 
Os achados diferenciados segundo categorias de investidores institucionais e o formato de suas participações nas firmas estão em linha com evidências de Ramalingegowda e Yu (2012) e Chen et al. (2015), de impacto diferenciado na prática do conservadorismo de participações de investidores institucionais, embora aqueles autores tenham utilizado a classificação de Bushee (2001) para diferenciar as categorias de investidores.

Com base nos achados, não se pôde rejeitar a hipótese de que categorias distintas de investidores institucionais interagem diferentemente quanto à demanda pelo atributo do conservadorismo condicional, com a sinalização de gestores em sua adoção de qualidade informacional no reporte de lucros contábeis, podendo-se inferir que qualidade informacional contábil está associada à demanda de investidores com objetivos racionais e profissionalmente definidos no sentido de maximização de risco/retorno de seus investimentos.

As evidências confirmaram a heterogeneidade das categorias de investidores institucionais no que tange à demanda por conservadorismo condicional, dada a influência explícita detectada para Fundos de Pensão, Fundos de Investimentos, Instituições Financeiras e Seguradoras, confirmando-se o argumento de Collins, Gong e Hribar (2003). Tais achados também sancionam os argumentos de Ball (2001) e Watts (2003) sobre a influência da demanda de investidores, indicando que antecipação tempestiva assimétrica de perdas e conservadorismo condicional seriam fruto de demanda informacional diferenciada entre categorias de investidores habilitados a operar com os conceitos contábeis de accruals.

\section{CONCLUSÃO}

Objetivou-se investigar a interação entre demanda informacional por investidores sofisticados e sinalização de informação contábil eficiente, ofertada com a adoção de conservadorismo condicional no reconhecimento e mensuração do lucro contábil por gestores no mercado brasileiro.

Tal interação seria esperada sob o argumento de que a sofisticação de investidores profissionais fornece habilidade para que se entenda o papel do conservadorismo condicional como sinalizador de lucros que refletem informação econômica capaz de orientar investidores nas suas expectativas acerca de proteção dos fluxos de caixa futuros a ser gerados pela firma.

Considerou-se, ao se utilizar de categorias de investidores institucionais como proxy para investidores sofisticados, que a heterogeneidade de interesses e de objetivos institucionais entre essas diferentes categorias de investidores institucionais (ganhos de longo prazo ou oportunidades de liquidez imediata, por exemplo) afetaria sua demanda por conservadorismo condicional. Ato contínuo, gestores seriam incentivados a sinalizar sobre sua situação econômica, no sentido de atrair tais investidores.

As evidências postas em relevo sugerem que investidores institucionais são diferenciadores de práticas de reconhecimento tempestivo assimétrico de perdas e de conservadorismo condicional, o que permite concluir que a demanda informacional desses investidores, tidos como sofisticados, exerce papel na qualidade informacional dos relatórios contábeis, corroborando pesquisas internacionais sobre o tema.

Tal efeito, de outra parte, se mostrou diferenciado segundo as categorias de investidores institucionais e segundo as formulações de sua participação nas firmas, confirmando-se o argumento de heterogeneidade desses agentes quanto à demanda por informação contábil útil e eficiente. Considerando-se as evidências apresentadas, o estudo é conclusivo quanto à possível fragilidade dos resultados de pesquisas ao se considerar investidores institucionais como categoria homogênea.

Avança-se na literatura, tanto internacional quanto nacional, por sinalizar efeito de categorias de investidores institucionais no conservadorismo condicional, consideradas de forma distinta daquela aplicada por Ramalingegowda e Yu (2012), com base em Bushee (2001); em função da indisponibilidade de dados para categorias de investidores institucionais ser tida como limitação ao 
estudo, a pesquisa contribui para aplicação de abordagem alternativa de classificação de investidores institucionais.

A pesquisa foi limitada também pela dificuldade em se obter informações sobre participação de investidores institucionais não relevantes no capital das firmas brasileiras, uma vez que não há obrigatoriedade de divulgação e de detalhamento destas participações por parte das firmas, conforme Instrução 480 de 7.12.2009 da Comissão de Valores Mobiliários (2009), motivo pelo qual se ateve à análise de participação relevante e de presença em órgãos de direção da firma.

$\mathrm{O}$ estudo fornece evidências que preenchem as seguintes lacunas de pesquisa no contexto brasileiro: (i) prática do conservadorismo condicional por firmas no Brasil, já refutada, genericamente, por Coelho e Lima (2007) e Paulo, Martins e Girão (2014), mas confirmada agora, condicionada à força da demanda informacional de investidores sofisticados; (ii) impacto distinto segundo categorias de investidores institucionais na demanda de informações contábeis de qualidade na postura dos gestores, não documentado por Holanda, Rebouças e Coelho (2013) e Lima et al. (2018) ao tomar o conjunto em bloco de investidores institucionais.

Também se complementa Moghaddam, Amirzadeh e Heidari (2013), fornecendo insights sobre a participação de diferentes categorias de investidores institucionais em órgãos diretivos das firmas na prática do conservadorismo condicional; os achados fornecem subsídios para maior compreensão da medida pela qual diferentes categorias optam por exercer ativismo de acionistas, com participação em órgãos decisórios das firmas. Em tal contexto, estudos futuros poderiam considerar o efeito de outras vias desse ativismo (formas de votação em assembleia, por exemplo) das categorias de investidores institucionais no conservadorismo condicional.

Direcionam-se, também, futuras pesquisas a explorar outros conceitos de investidores sofisticados e seu relacionamento com as decisões de gestores em sinalizar lucros com qualidade informacional em mercados emergentes, inclusive com a consideração de outros modelos de detecção de qualidade informacional - persistência dos lucros e value relevance dos números contábeis, por exemplo - reexaminando a força da demanda de investidores sofisticados em influenciar a oferta da informação contábil de qualidade, conforme propõem Ball (2001) e Watts (2003).

Estritamente, do ponto de vista da representação do conservadorismo condicional, há que sugerir medidas alternativas, como o modelo de Khan e Watts (2009), que tanto individualiza tal medida por firma, como emprega variáveis adicionais para tal estimação.

Por fim, também se sugerem estudos que aprofundem a discussão sobre motivações que levam categorias específicas de investidores a atitudes diversas em torno da demanda por números contábeis informacionalmente eficientes, com suporte no argumento de que há tanto categorias de investidores institucionais que se baseiam em conteúdo informacional para suas decisões, quanto categorias que operam sem a consideração de análise fundamentalista para suas decisões de investimento, conforme Collins, Gong e Hribar (2003).

\section{REFERÊNCIAS}

Ahmed, A. S., Neel, M., \& Wang, D. (2013). Does mandatory adoption of IFRS improve accounting quality? Preliminary evidence. Contemporary Accounting Research, 30(4), 1344-1372.

Akerlof, G. (1970). The Market for «Lemons»: Quality Uncertainty and the Market Mechanism "in Quarterly Journal of Economics, 84.

Arellano, M., \& Bond, S. (1991). Some tests of specification for panel data: Monte Carlo evidence and an application to employment equations. The Review of Economic Studies, 58(2), $277-297$.

Ball, R. (2001). Infrastructure requirements for an economically efficient system of public financial reporting and disclosure. Brookings-Wharton Papers on Financial Services, 2001(1), 127-169.

Ball, R., \& Shivakumar, L. (2005). Earnings quality in UK private firms: comparative loss recognition timeliness. Journal of Accounting and Economics, 39(1), 83-128.

Barros, L. A. B. C., Junior, F. H. F. C., Silveira, A. D., \& Bergmann, D. R. (2010). A questão da endogeneidade nas pesquisas empíricas em finanças corporativas: principais problemas e formas 
de mitigação. Social Science Research Network. Disponível em:

http://papers.ssrn.com/sol3/papers.cfm?abstract_id=1593187. Acesso em: 02 ago. 2016.

Barth, M. E., Landsman, W. R., \& Lang, M. H. (2008). International accounting standards and accounting quality. Journal of Accounting Research, 46(3), 467-498.

Basu, S. (1997). The conservatism principle and the asymmetric timeliness of earnings. Journal of Accounting and Economics, 24(1), 3-37.

Brickley, J. A., Lease, R. C., \& Smith Jr, C. W. (1988). Ownership structure and voting on antitakeover amendments. Journal of Financial Economics, 20, 267-291.

Bushee, B. J. (1998). The influence of institutional investors on myopic R\&D investment behavior. Accounting Review, 305-333.

Bushee, B. J. (2001). Do institutional investors prefer near-term earnings over long-run value?. Contemporary Accounting Research, 18(2), 207-246.

Chen, X., Harford, J., \& Li, K. (2007). Monitoring: Which institutions matter?. Journal of Financial Economics, 86(2), 279-305.

Chen, Y., Li, L., Wang, H., \& Wang, P. (2015). Institutional investors and conservative financial reporting: evidence from China. Eurasian Economic Review, 5(1), 161-178.

Chi, W., Liu, C., \& Wang, T. (2009). What affects accounting conservatism: A corporate governance perspective. Journal of Contemporary Accounting \& Economics, 5(1), 47-59.

Coelho, A. C. D. (2007) Qualidade informacional e conservadorismo nos resultados contábeis publicados no Brasil (Tese de Doutorado). Faculdade de Economia, Administração e Contabilidade, Universidade de São Paulo, Programa de Pós-Graduação em Controladoria e Contabilidade, São Paulo.

Coelho, A. C. D., de Sales Cia, J. N., \& Lima, I. S. (2010). Conservadorismo condicional na divulgação de lucros em companhias abertas brasileiras: diferenças entre emissoras e não emissoras de ADR e entre sistemas contábeis. RAM. Revista de Administração Mackenzie, 11(1), 117-149.

Coelho, A. C., Galdi, F. C., \& Lopes, A. B. (2017). Determinants of asymmetric loss recognition timeliness in public and private firms in Brazil. Emerging Markets Review, 31, 65-79.

Coelho, A. C., \& Lima, I. S. (2007). Qualidade informacional e conservadorismo nos resultados contábeis publicados no Brasil. Revista Contabilidade \& Finanças, 18(45), 38-49.

Coelho, A. C., \& Lima, I. S. (2008). Funções informacionais de apropriações contábeis pelo regime de competência. Revista Base (Administração e Contabilidade) da UNISINOS, 5(2), 120-130.

Collins, D. W., Gong, G., \& Hribar, P. (2003). Investor sophistication and the mispricing of accruals. Review of Accounting Studies, 8(2-3), 251-276.

Connelly, B. L., Certo, S. T., Ireland, R. D., \& Reutzel, C. R. (2011). Signaling theory: A review and assessment. Journal of Management, 37(1), 39-67.

Crisóstomo, V. L., \& González, E. V. (2006). Possível estratégia de ativismo de fundos de pensão no Brasil. Revista de Economia Contemporânea, 10(1).

Davis, E. P., \& Steil, B. (2004). Institutional investors. MIT press.

Dechow, P. M., \& Dichev, I. D. (2002). The quality of accruals and earnings: The role of accrual estimation errors. The Accounting Review, 77(s-1), 35-59.

Francis, J., LaFond, R., Olsson, P., \& Schipper, K. (2003, February). Accounting anomalies and information uncertainty. In AFA 2004 San Diego Meetings.

Gaspar, J. M., Massa, M., \& Matos, P. (2005). Shareholder investment horizons and the market for corporate control. Journal of Financial Economics, 76(1), 135-165.

Gillan, S. L., \& Starks, L. T. (2000). Corporate governance proposals and shareholder activism: The role of institutional investors. Journal of Financial Economics, 57(2), 275-305.

Givoly, D., \& Hayn, C. (2000). The changing time-series properties of earnings, cash flows and accruals: Has financial reporting become more conservative? Journal of Accounting and Economics, 29(3), 287-320.

Gujarati, D. N., \& Porter, D. C. (2011). Econometria Básica-5. Amgh Editora.

Gulati, R., \& Higgins, M. C. (2003). Which ties matter when? The contingent effects of interorganizational partnerships on IPO success. Strategic Management Journal, 24(2), 127-144.

Gupta, A. K., Govindarajan, V., \& Malhotra, A. (1999). Feedback-seeking behavior within multinational corporations. Strategic Management Journal, 20(3), 205-222. 
Holanda, A. P., Rebouças, S. M. D. P., \& Coelho, A. C. D. (2013). Gerenciamento de resultados e presença de investidores institucionais nas firmas brasileiras. Contexto, 13(25).

Instrução CVM n. 480, de 7 de dezembro de 2009. Dispõe sobre o registro de emissores de valores mobiliários admitidos à negociação em mercados regulamentados de valores mobiliários (CVM). Disponível em: http://www.cvm.gov.br/export/sites/cvm/legislacao/instrucoes/anexos/400/inst480consolid.pdf. Acesso em: 1 dez. 2016.

Khan, M., \& Watts, R. L. (2009). Estimation and empirical properties of a firm-year measure of accounting conservatism. Journal of Accounting and Economics, 48(2-3), 132-150.

Lafond, R., \& Roychowdhury, S. (2008). Managerial ownership and accounting conservatism. Journal of Accounting Research, 46(1), 101-135.

Leland, H. E., \& Pyle, D. H. (1977). Informational asymmetries, financial structure, and financial intermediation. The Journal of Finance, 32(2), 371-387.

Lima, G. A. S. F., Góis, A. D., De Luca, M. M. M., \& Sousa, E. P. D. (2018). Effect of institutional investor participation on price lead earnings and earnings quality: international evidence. Journal of International Accounting Research, 17(1), 103-119.

Liu, S. D., \& Skerratt, L. (2014). Earnings quality across listed, medium-sized, and small companies in the UK. Brunel Univ. West London, Brunel Business School.

Marques, A. E. C., Holanda, A. P., \& Coelho, A. C. D. (2012). Qualidade informacional dos lucros e firmas de auditoria: evidências no Brasil. Advances in Scientific and Applied Accounting, 5(2), 157-180.

Moghaddam, A., Amirzadeh, V., \& Heidari, A. A. (2013). Studying the Relationship between Institutional Ownership and Conservatism in Companies Accepted in Tehran Stock Exchange. International Journal of Academic Research in Accounting, Finance and Management Sciences, 3(1), 400-408.

Myers, S. C. (1984). The capital structure puzzle. The Journal of Finance, 39(3), 574-592.

Myers, S. C., \& Majluf, N. S. (1984). Corporate financing and investment decisions when firms have information that investors do not have. Journal of Financial Economics, 13(2), 187-221.

Paulo, E., Martins, E., \& Pontes Girão, L. F. D. A. (2014). Accounting information quality in Latin-and North-American public firms. In Accounting in Latin America (pp. 1-39). Emerald Group Publishing Limited.

Pincus, M., Rajgopal, S., \& Venkatachalam, M. (2007). The accrual anomaly: International evidence. The Accounting Review, 82(1), 169-203.

Portugal, M. (2010). Investidores institucionais crescem, mas são limitados por pouca diversificação. Exame.com, São Paulo. Disponível em: http://exame.abril.com.br/mercados/noticias/investidoresinstitucionais-crescem-brasil-saolimitados-falta-diversificacao-576503. Acesso em: 23 mar. 2016.

Pucheta-Martínez, M. C., \& García-Meca, E. (2014). Institutional investors on boards and audit committees and their effects on financial reporting quality. Corporate Governance: An International Review, 22(4), 347-363.

Ramalingegowda, S., \& Yu, Y. (2012). Institutional ownership and conservatism. Journal of Accounting and Economics, 53(1-2), 98-114.

Ross, S. A. (1977). The determination of financial structure: the incentive-signalling approach. The Bell Journal of Economics, 23-40.

Sarlo Neto, A., Bassi, B. R., \& de Almeida, A. A. (2011). Um estudo sobre a informatividade dos lucros contábeis na América Latina. Revista de Contabilidade e Organizações, 5(12), 4-25.

Spence, M. (1978). Job market signaling. In Uncertainty in Economics (pp. 281-306). Academic Press.

Spence, M. (2002). Signaling in retrospect and the informational structure of markets. American Economic Review, 92(3), 434-459.

Telles, S. V., \& Salotti, B. M. (2015). Divulgação da informação contábil sobre depreciação: o antes e o depois da adoção das IFRS. Revista Universo Contábil, 11(2), 153-173.

Velury, U., \& Jenkins, D. S. (2006). Institutional ownership and the quality of earnings. Journal of Business Research, 59(9), 1043-1051.

Watts, R. L. (2003). Conservatism in accounting part I: Explanations and implications. Accounting Horizons, 17(3), 207-221.

Windmeijer, F. (2005). A finite sample correction for the variance of linear efficient two-step GMM estimators. Journal of Econometrics, 126(1), 25-51. 